\title{
The influence of only and even on online semantic interpretation
}

\author{
RUTH FILIK \\ University of Nottingham, Nottingham, England \\ Kevin B. Paterson \\ University of Leicester, Leicester, England \\ AND \\ SIMON P. LIVERSEDGE \\ University of Southampton, Southampton, England
}

\begin{abstract}
Focus particles such as only and even indicate that the focused element(s) in a sentence should be contrasted with a set of contextually defined alternatives. Only indicates that properties assigned to the focus set are not shared by elements of the alternative set, whereas even indicates that the focus and alternative sets share the properties mentioned in the sentence. Even has the additional function of marking the focused element as being low on a scale of alternatives ranked in terms of likelihood, thereby signaling that what is being described is somewhat surprising. Using eyetracking, we demonstrate that contrast information associated with only and even is rapidly processed online, with effects for even being delayed, as compared with only (Experiment 1). This difference in time course was not driven by the underlying semantics of the sentence without the focus particle (Experiment 2) but was probably due to even's more complex semantic function.
\end{abstract}

In order to fully understand a text, readers often must make inferences based on situational or world knowledge. Certain linguistic devices facilitate this process. For instance, words such as only and even are commonly used to indicate that a particular entity or event is to be contrasted with a set of (often implicit) alternatives. Furthermore, even can signal that what is being described may be unexpected or surprising. We investigate how readers process sentences containing only and even - specifically, how these devices influence the processing of subsequent material.

Only and even are known as focus-sensitive particles, because of their tendency to associate with a focused constituent in a sentence, with the range of constituents over which they exert their effect known as their scope (e.g., Jackendoff, 1972; König, 1991). A constituent is focused by the placing of stress by phonological or syntactic means, in order to mark new information or indicate that a contrast is to be made between the focused information and some alternatives (e.g., Jackendoff, 1972; Rooth, 1992). For example, in Sentence 1 (where capitals indicate the placement of phonological stress), focus is assigned to Mary, and readers will understand the sentence as asserting that it was Mary who kissed John, rather than some alternative.

\section{Only MARY kissed John}

The alternatives to Mary must be inferred by the reader. In principle, anything belonging to the same semantic cat- egory (in this case, probably another person or, possibly, anything that can kiss) could be an alternative, but realistically this set of possible alternatives is restricted by situational knowledge.

Exclusive focus particles (e.g., only, just) indicate that properties assigned to the focus set are not shared by the alternatives (König, 1991). For example, if someone utters Only Mary kissed John, they are indicating that Mary, and no one else, kissed John. Inclusive particles, (e.g., even, also, too ) indicate that the focus set and the alternatives share a property. Consider the following example:

\section{Even MARY kissed John.}

Sentence 2 asserts that Mary kissed John and that there is a set of contextually salient alternatives who also kissed John. This additive contrastive function of even is shared by particles like also and too. The additional function served by even, but not by also and too, is that the alternatives are ranked on a likelihood scale in relation to the described event (Horn, 1989; Kay, 1990), with the focused element (e.g., Mary) being ranked at the lower end of the scale (for discussions of the semantics of even, see, e.g., Bennett, 1982; Fauconnier, 1975; Giannakidou, 2007; Kartunnen \& Peters, 1979; Lycan, 1991). For example, the felicitousness of Sentence 2 depends on the focused element (Mary) being less likely than some contextually defined alternatives - that is,

R. Filik, ruth.filik@nottingham.ac.uk 
other people who had kissed John. As a consequence, the focused element is characterized as an unexpected or surprising one in relation to the described event (e.g., Francescotti, 1995).

Relatively little psycholinguistic research has investigated how these devices influence online language comprehension, with existing work concentrating on the influence of only on the processing of syntactic ambiguities (following Ni, Crain, \& Shankweiler, 1996; see also Filik, Paterson, \& Liversedge, 2005; Liversedge, Paterson, \& Clayes, 2002; Paterson, Liversedge, \& Underwood, 1999; Sedivy, 2002) or the acquisition of semantics (Paterson, Liversedge, Rowland, \& Filik, 2003). There has been much less research into the nature of the contrasts these words elicit, but see Paterson et al. (2007) for evidence that contrastive focus is computed online during sentence processing. To our knowledge, there are currently no studies on how other focus particles influence online semantic interpretation.

As was noted earlier, focus particles not only carry information about contrasts, but also can induce linguistic expectations. Whether or not the information provided matches a reader's expectations (as determined by their world knowledge and the content of the text) has an impact on the perceived felicitousness of the text. For example, consider Sentences 3 and 4 below:

3. Only students taught by the best teacher passed the examination in the summer.

4. Only students taught by the worst teacher passed the examination in the summer.

Passing an examination may be considered more likely for students taught by the best teacher than for those taught by the worst teacher (note that a criterion by which a teacher's quality may be assessed is whether or not their students pass exams). Thus, events described in Sentence 3 may be perceived as more felicitous, in relation to world knowledge, than those in Sentence 4. Specifically, in Sentence 3, the information conveyed is congruent with the contrast set up by only. In the absence of context, if we were told that any one group of students had passed an exam (to the exclusion of others), students taught by the best teacher would be a highly likely set, given our world knowledge. In contrast, Sentence 4, in the absence of any explanatory context, sounds somewhat less likely.

Previous research (e.g., Filik, 2008; Ni, Fodor, Crain, \& Shankweiler, 1998; Rayner, Warren, Juhasz, \& Liversedge, 2004; Staub, Rayner, Pollatsek, Hyönä, \& Majewski, 2007; Warren \& McConnell, 2007) indicates that disruption to sentence processing by information that is incongruent with the reader's world knowledge can be readily detected in the eye movement record. In terms of the present study, Sentence 4 becomes less felicitous than Sentence 3 at passed the examination; hence, this is the first place that we may expect to see disruption. Given what we know about the semantics of even, consider Sentence 5 and Sentence 6:

5. Even students taught by the best teacher passed the examination in the summer.

6. Even students taught by the worst teacher passed the examination in the summer.

With the minimal change of substituting even for only, the felicity of the sentences is reversed. Since even signals an unexpected event, it now becomes felicitous to state that students taught by the worst teacher passed the exam, since this event may be somewhat surprising and thus fits with the use of even. On the other hand, Sentence 5 now sounds incongruent, since the information conveyed is not surprising and, therefore, does not justify the use of even. Thus, one way to investigate how these devices influence online sentence processing is to examine what happens when the semantic properties of the focus particle are congruent or incongruent with information supplied by subsequent text (as in Sentences 3 and 6 and Sentences 4 and 5 , respectively).

\section{EXPERIMENT 1}

We recorded participants' eye movements as they read sentences containing only and even (see Table 1). As was discussed previously, only and even have different semantic properties. Only excludes contextually relevant alternatives, whereas even includes them and has the additional property of signaling that what is being described is unexpected. If these operations occur online, we would predict shorter reading times for sentences beginning with only that describe a likely event (e.g., 3) than for those describing an unlikely event (e.g., 4). Following theoretical accounts of the function of even, we would predict the opposite pattern of effects for sentences beginning with even. Specifically, reading times should be shorter for sentences containing even that describe a normally unlikely event (e.g., 6) than for those describing a likely event (e.g., 5). We would expect these differences to emerge on, or after, inspection of the verb phrase (e.g., passed the examination), since this is where the congruency between the outcome of the described event and the use of each focus particle first becomes apparent.

Table 1

[Only/Even] students taught $1 \mid$ by the [best/worst] teacher ${ }_{2} \mid$ passed the examination $_{\text {Critical }} \mid$ in the summer. Postcritical [Only/Even] customers served $d_{1} \mid$ by the [politest/rudest] waiter $_{2} \mid$ left a tip Critical $\mid$ after their meal. Postcritical $\mid$

[Only/Even] countries represented ${ }_{1} \mid$ by the [strongest/weakest] army $_{2} \mid$ won the battle Critical $_{\mid} \mid$in the desert. Postcritical $\mid$ [Only/Even] travellers transported $1 \mid$ by the [fastest/slowest] $\operatorname{train}_{2}\left|\operatorname{arrived~on~time~}_{\text {Critical }}\right|$ at their destination. Postcritical $\mid$

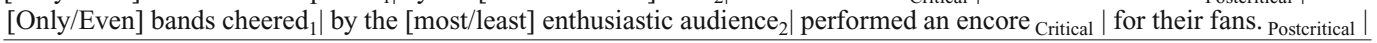




\section{Method}

Participants. Forty native English speakers from the University of Glasgow community participated.

Materials and Design. Twenty-four experimental items were designed. Sentences began with only or even. The focus set was either relatively likely (e.g., students taught by the best teacher) or unlikely (e.g., students taught by the worst teacher) to be engaged in the event described in the critical region (e.g., passed the examination), on the basis of world knowledge. Thus, the experiment employed a 2 particle (only vs. even $) \times 2$ likelihood (likely vs. unlikely) design.

Items were presented in four counterbalanced lists so that each participant saw only one version of each but saw an equal number of items in each condition. Each list also contained 74 fillers, none of which contained only or even. Items were presented in fixed pseudorandom order, beginning with two practice sentences. Each item spanned two lines, with two blank lines between each line of text. The critical region (e.g., passed the examination) never appeared at the beginning or end of a line, always comprised three words, and was from 8 to 21 characters long $(M=14, S D=3.7)$. The postcritical region was always three words and was from 10 to 18 characters long $(M=13, S D=2.3)$. Comprehension questions followed $50 \%$ of the experimental and filler items.

Apparatus and Procedure. Eye movements were recorded using a Fourward Technologies Generation 5.5 DPI eyetracker at the University of Glasgow, employing standard stimulus presentation and data acquisition procedures.

Analysis. Materials were divided into analysis regions (see Table 1). The critical region contained a phrase (e.g., passed the examination) where it became clear whether the sentence described a more or less likely set of circumstances. The postcritical region was the remainder of the sentence.

Following standard procedures, trials were deleted in which no first-pass fixations were made in two or more adjacent regions (accounting for $0.3 \%$ of the trials). The participants responded correctly to $95.4 \%$ of the comprehension questions, with no significant differences between conditions $(F<2.6)$.

Eye movement measures. We report three eye movement measures. First-pass reading time sums all fixations in a region until the point of fixation exits the region to the left or the right and provides an index of initial processing effects. Regression path reading time is the sum of fixations from the time that a region is first entered from the left until it is first exited to the right. This measure includes fixations made to reinspect earlier portions of text and provides an indication of early processing difficulty, along with time spent reinspecting text in order to recover from such difficulty (e.g., Liversedge, Paterson, \& Pickering, 1998; Rayner \& Duffy, 1986). Total reading time sums all fixations within a region and provides a measure of overall comprehension difficulty at this region.

Trials on which the region of interest was skipped in first-pass and regression path reading times were excluded from the analysis. Reading time data are reported for critical and postcritical regions only, since text in preceding regions differed in content across conditions. However, in order to further investigate how readers attempted to overcome processing difficulty, regressions in are reported for Regions 1 and 2. This measure indicates the proportion of trials on which a reader made a regressive eye movement into a region and provides an indication of the probability of reinspecting particular portions of text. If it is indeed the case that even signals the appearance of unexpected information and that this process occurs online, the subsequent description of relatively likely circumstances is incongruent with the use of even. Thus, readers may make more regressions back to the beginning of the sentence in this condition, in order to reevaluate the sentence in terms of their expectations.

\section{Results}

Condition-by-region means for each measure are reported in Table 2. Data for each region were subjected to two particle (only vs. even) $\times$ likelihood (likely vs. unlikely) repeated measures ANOVAs, treating participants $\left(F_{1}\right)$ and items $\left(F_{2}\right)$ as random variables.

Critical region. First-pass reading times showed no significant main effects $\left(F_{\mathrm{s}}<1.7\right)$, but the interaction was reliable by participants and approached significance by items $\left[F_{1}(1,39)=5.94, p<.05 ; F_{2}(1,23)=3.97, p<\right.$ .06]. Reading times were longer for sentences with only when the focused set was unlikely to be engaged in the event described in the critical region $\left[F_{1}(1,39)=5.88\right.$, $\left.p<.05 ; F_{2}(1,23)=5.39, p<.05\right]$. This suggested that readers had immediately detected the infelicitous nature of these stimuli and, thus, had rapidly computed the contrast information implicit in only. For sentences with even, there was no difference between likelihood conditions $(F s<1.1)$. Thus, even did not immediately reverse the likelihood effect found for sentences with only.

There were no significant effects in regression path reading times $(F \mathrm{~s}<1.4)$. Although total reading times showed no significant main effects $(F \mathrm{~s}<3.1)$, there was an interaction $\left[F_{1}(1,39)=5.86, p<.05 ; F_{2}(1,23)=5.29\right.$, $p<.05]$. Following only, total reading times were longer for sentences containing unlikely than for those containing likely information $\left[F_{1}(1,39)=6.36, p<.05 ; F_{2}(1,23)=\right.$ $6.64, p<.05]$, but there was no likelihood effect for sentences with even $(F \mathrm{~s}<1)$.

Postcritical region. First-pass reading times showed no significant main effects $\left(F_{\mathrm{S}}<2.3\right)$, but there was an interaction $\left[F_{1}(1,39)=5.21, p<.05 ; F_{2}(1,23)=6.20\right.$,

Table 2

Descriptive Statistics for Experiment 1

\begin{tabular}{|c|c|c|c|c|c|c|c|c|c|}
\hline \multirow[b]{3}{*}{ Region } & \multirow[b]{3}{*}{ Measure } & \multicolumn{4}{|c|}{ Only } & \multicolumn{4}{|c|}{ Even } \\
\hline & & \multicolumn{2}{|c|}{ Likely } & \multicolumn{2}{|c|}{ Unlikely } & \multicolumn{2}{|c|}{ Likely } & \multicolumn{2}{|c|}{ Unlikely } \\
\hline & & $M$ & $\overline{S E}$ & $M$ & $\overline{S E}$ & $M$ & $\overline{S E}$ & $M$ & $S E$ \\
\hline 1 & Regressions in $(\%)$ & 29.2 & 3.9 & 33.1 & 3.8 & 41.3 & 4.2 & 27.5 & 4.0 \\
\hline 2 & Regressions in (\%) & 12.9 & 2.1 & 13.0 & 2.4 & 12.1 & 2.4 & 14.6 & 2.3 \\
\hline Critical & $\begin{array}{l}\text { First pass (msec) } \\
\text { Regression path (msec) } \\
\text { Total time (msec) }\end{array}$ & $\begin{array}{l}540 \\
634 \\
629\end{array}$ & $\begin{array}{l}18.5 \\
21.1 \\
19.5\end{array}$ & $\begin{array}{l}604 \\
661 \\
702\end{array}$ & $\begin{array}{l}30.7 \\
31.7 \\
37.4\end{array}$ & $\begin{array}{l}569 \\
643 \\
659\end{array}$ & $\begin{array}{l}21.2 \\
21.5 \\
20.2\end{array}$ & $\begin{array}{l}547 \\
664 \\
652\end{array}$ & $\begin{array}{l}22.5 \\
34.7 \\
30.2\end{array}$ \\
\hline Postcritical & $\begin{array}{l}\text { First pass (msec) } \\
\text { Regression path (msec) } \\
\text { Total time (msec) }\end{array}$ & $\begin{array}{l}550 \\
724 \\
592\end{array}$ & $\begin{array}{l}17.7 \\
28.7 \\
18.5\end{array}$ & $\begin{array}{l}571 \\
899 \\
657\end{array}$ & $\begin{array}{l}25.9 \\
56.8 \\
29.8\end{array}$ & $\begin{array}{l}602 \\
920 \\
675\end{array}$ & $\begin{array}{l}23.8 \\
60.5 \\
29.0\end{array}$ & $\begin{array}{l}541 \\
772 \\
615\end{array}$ & $\begin{array}{l}18.5 \\
44.6 \\
21.5\end{array}$ \\
\hline
\end{tabular}


$p<.05]$. Following only, there was no significant likelihood effect $\left(F_{\mathrm{S}}<1\right)$. However, following even, first-pass reading times were shorter when sentences described a relatively unlikely set of circumstances $\left[F_{1}(1,39)=8.75\right.$, $\left.p<.01 ; F_{2}(1,23)=6.81, p<.05\right]$, indicating that the semantic information associated with even had a later influence than did that associated with only.

Regression path reading times showed no significant main effects $\left(F_{\mathbf{S}}<1.3\right)$, but there was an interaction $\left[F_{1}(1,39)=16.36, p<.01 ; F_{2}(1,23)=12.20, p<.01\right]$. Following only, regression path reading times were longer for sentences containing unlikely than for those containing likely information $\left[F_{1}(1,39)=11.84, p<.01\right.$; $\left.F_{2}(1,23)=7.60, p<.05\right]$, but for sentences with even, the reverse was found, with longer regression path reading times for sentences containing normally likely than for those containing unlikely information $\left[F_{1}(1,39)=6.21\right.$, $\left.p<.05 ; F_{2}(1,23)=5.13, p<.05\right]$. Therefore, in regression path reading times for the postcritical region, we see the full crossover effect expected for sentences with only and even.

This pattern of effects was also observed in total reading times, in which there was an interaction $\left[F_{1}(1,39)=\right.$ $\left.11.42, p<.01 ; F_{2}(1,23)=11.71, p<.01\right]$ and no significant main effects $\left(F_{\mathrm{S}}<1.4\right)$. Following only, total reading times were longer for sentences containing unlikely information $\left[F_{1}(1,39)=6.81, p<.05 ; F_{2}(1,23)=5.64, p<\right.$ $.05]$, but following even, total reading times were longer for sentences containing normally likely information, although this effect was marginal by items $\left[F_{1}(1,39)=7.39\right.$, $\left.p<.01 ; F_{2}(1,23)=3.44, p<.08\right]$.

Regressions into Regions 1 and 2. Regressions into Region 1 showed no significant main effects $\left(F_{\mathrm{s}}<2.6\right)$, but there was an interaction $\left[F_{1}(1,39)=9.46, p<.01\right.$; $\left.F_{2}(1,23)=5.45, p<.05\right]$. For sentences with only, there were no differences between likelihood conditions $\left(F_{\mathbf{S}}<\right.$ 1.1), whereas for sentences with even, there were significantly more regressions into Region 1 when sentences described likely rather than unlikely events $\left[F_{1}(1,47)=\right.$ $\left.11.60, p<.01 ; F_{2}(1,23)=4.67, p<.05\right]$, possibly reflecting the readers' desire to reevaluate the "likely" subject in the even sentences, in order to integrate information about expectations. This would provide further evidence that sentences containing only and even are processed differently. There were no significant effects for regressions into Region $2\left(F_{\mathrm{s}}<1\right)$.

\section{EXPERIMENT 2}

The results from Experiment 1 could be interpreted as evidence for a process of online semantic interpretation that takes account of the different semantic properties of focus particles. Following only, readers had more difficulty processing sentences that described unlikely events than they did processing sentences that described likely events. However, the inclusion of even reversed this effect, creating a situation in which readers had more difficulty processing sentences that described normally likely events. Effects were observed earlier in the eye movement
Table 3

Descriptive Statistics for Experiment 2

\begin{tabular}{|c|c|c|c|c|c|}
\hline \multirow[b]{2}{*}{ Region } & \multirow[b]{2}{*}{ Measure (msec) } & \multicolumn{2}{|c|}{ Likely } & \multicolumn{2}{|c|}{ Unlikely } \\
\hline & & $M$ & $S E$ & $M$ & $S E$ \\
\hline \multirow[t]{3}{*}{ Critical } & First pass & 565 & 26.0 & 570 & 21.2 \\
\hline & Regression path & 695 & 41.0 & 682 & 30.2 \\
\hline & Total time & 749 & 34.7 & 774 & 33.2 \\
\hline \multirow[t]{3}{*}{ Postcritical } & First pass & 595 & 35.4 & 590 & 32.5 \\
\hline & Regression path & 1,281 & 127.5 & 1,365 & 104.8 \\
\hline & Total time & 716 & 42.4 & 730 & 38.0 \\
\hline
\end{tabular}

record for only than for even, possibly because of its more complex semantics.

However, another possibility was that differences in the time course of first-pass effects for only and even were driven by the underlying semantics of the sentence. That is, readers might have had difficulty with sentences that described apparently unlikely events (e.g., that students taught by the worst teacher passed an examination), regardless of which particle was used. If so, this factor might have speeded the onset of disruption with only (which clashes with the low-scale value worst teacher) but slowed the onset of disruption with even (which is consistent with the low-scale value). Thus, it may be that delayed effects for even were not due to its more complex semantic function, but that its interpretation went against an underlying baseline effect. Therefore, we carried out an additional experiment to examine whether a likelihood effect would emerge when sentences did not include a focus particle.

Twenty-two native English speakers from the University of Leicester had their eye movements monitored while reading the stimuli from Experiment 1, but with the instead of only or even (e.g., The students taught by the best/worst teacher passed the examination in the sum$m e r)$, along with 40 unrelated filler items. Presentation, data acquisition, and analysis procedures were the same as those in Experiment 1. There was 5.3\% data loss due to track loss, and the participants answered $95 \%$ of the comprehension questions correctly, with no differences across conditions $(t<1)$.

Condition-by-region means for each measure are reported in Table 3 . There were no significant differences in any region or measure $(t \mathrm{~s}<1.2)$. We note that regression path reading times for the postcritical region were numerically longer in the unlikely condition, providing some evidence (although not approaching significance) that the participants had detected the mildly infelicitous nature of these sentences. Importantly, however, there were no significant differences in first-pass reading times for either region, indicating that the difference in first-pass effects for only and even in Experiment 1 was not dependent on underlying likelihood effects.

Regression path reading times for the postcritical region were longer in Experiment 2 than in Experiment 1. In the materials in Experiment 2, set-splitting took place by virtue of the relative clause. However, since there was no focus particle to indicate that a contrast must be made, no strong likelihood effects were observed. Since this pro- 
cess of set-splitting may operate differently in the absence of a focus particle, its effects may have impacted on later aspects of sentence processing.

\section{DISCUSSION}

The results indicate that contrast information associated with focus particles is computed online. In Experiment 1 , for sentences with only, when the focus set was incongruent with events described in the critical region, this incongruence would appear to have been calculated relatively rapidly, as indicated by first-pass reading times on the critical region (which was the earliest point in the sentence at which the incongruity became apparent). This supports and extends the findings of Paterson et al. (2007), who also found that contrastive focus for sentences containing only is computed online. In their manipulation, the nature of the alternative set was made explicit in the sentence, whereas in the present study, the alternative set had to be inferred. Thus, the present results suggest that computation of contrastive focus for sentences containing only occurs rapidly during online sentence comprehension even when appropriate contrast information is not explicitly provided.

For sentences with even, the results from Experiment 1 showed that the evaluation of the focus set in relation to subsequent information is delayed, relative to sentences with only. It was not until the postcritical region that even had the predicted effect and produced longer reading times when the sentence described a relatively likely set of events. One possibility is that this difference in time course reflects slower computation and evaluation of contrastive focus for even than for only. However, it was also possible that this difference was due to an interaction between the focus particle and the underlying semantics of the sentences. Specifically, if the underlying semantics was consonant with the function of only (rather than even), this might explain why incongruity effects were observed earlier when sentences included only. Experiment 2 was conducted to further investigate this possibility and revealed no incongruity effects when sentences did not include a focus particle. Therefore, there was no evidence that underlying semantics supported the earlier detection of an incongruity when sentences included only rather than even.

Thus, the lateness of effects for even, relative to sentences with only, is likely to reflect the more complex semantic function of even. Both particles share the function of splitting sets and highlighting that the focused set should be contrasted with a set of alternatives. In addition to this, even indicates that the focused set is less likely than some contextually defined alternatives to have the property ascribed to it. In this way, even conveys that information may be unexpected or surprising. It seems probable that the operations required to do this take time, resulting in delayed effects for even.

In Experiment 1, there were more regressions back to Region 1 when sentences with even described a normally likely set of events. This finding may reflect readers' de- sire to reevaluate the subject of the sentence in relation to their expectations. Specifically, since the presence of even signals the appearance of unexpected information, the subsequent description of relatively likely circumstances is incongruent with its use. Thus, the subject of the sentence would need to be reevaluated in relation to expectations in order to achieve a felicitous interpretation (see Mitchell, Shen, Green, \& Hodgson, 2008, for a discussion of the factors involved in guiding regressive eye movements). Other recent evidence also suggests that readers make regressions in order to evaluate current information in relation to expectations (Moxey, Filik, \& Paterson, 2009). However, this issue has so far been relatively underexplored.

Research into the influence of focus particles on language comprehension has, to date, principally concentrated on how a single particle, only, exerts its influence. Our data provide clear and novel evidence that different particles have markedly different properties, as suggested by linguistic theories that specify that one function of even is to signal the appearance of unexpected information. Thus far, theories have been based largely on intuitive judgments, rather than on empirical data. We have shown that focus particles do more than simply splitting discourse entities into focused and alternative sets; they also have subtle and complex pragmatic properties that affect how language is processed. Our evidence suggests that these additional functions incur particular processing costs and that this may affect how rapidly semantic information is evaluated and the time course of incongruity detection during sentence processing.

\section{AUTHOR NOTE}

This research was supported by ESRC Grant RES-062-23-0002. Many thanks to Antje Sauermann for assistance with data collection, and to two anonymous reviewers for their helpful comments and suggestions. Correspondence concerning this article should be addressed to R. Filik, School of Psychology, University of Nottingham, University Park, Nottingham NG7 2RD, England (e-mail: ruth.filik@nottingham.ac.uk).

\section{REFERENCES}

Bennett, J. (1982). Even if. Linguistics \& Philosophy, 5, 403-418.

Fauconnier, G. (1975). Pragmatic scales and logical structure. Linguistic Inquiry, 6, 353-375.

FILIK, R. (2008). Contextual override of pragmatic anomalies: Evidence from eye movements. Cognition, 106, 1038-1046. doi:10.1016/j .cognition.2007.04.006

Filik, R., Paterson, K. B., \& Liversedge, S. P. (2005). Parsing with focus particles in context: Eye movements during the processing of relative clause ambiguities. Journal of Memory \& Language, 53, 473 495. doi:10.1016/j.jml.2005.07.004

Francescotti, R. M. (1995). Even: The conventional implicature approach reconsidered. Linguistics \& Philosophy, 18, 153-173.

GIANNAKIDOU, A. (2007). The landscape of EVEN. Natural Language \& Linguistic Theory, 25, 39-81. doi:10.1007/s11049-006-9006-5

Horn, L. R. (1989). A natural history of negation. Chicago: Chicago University Press.

JACKENDOFF, R. (1972). Semantic interpretation in generative grammar. Cambridge, MA: MIT Press.

Kartunnen, L., \& Peters, S. (1979). Conventional implicatures. In C. Oh \& D. Dinneen (Eds.), Syntax and semantics II: Presuppositions (pp. 1-56). New York: Academic Press.

KAY, P. (1990). Even. Linguistics \& Philosophy, 13, 59-111. 
KöNIG, E. (1991). The meaning of focus particles. London: Routledge. Liversedge, S. P., Paterson, K. B., \& Clayes, E. L. (2002). The influence of "only" on syntactic processing of "long" relative clause sentences. Quarterly Journal of Experimental Psychology, 55A, 225-240. doi:10.1080/02724980143000253

Liversedge, S. P., Paterson, K. B., \& Pickering, M. J. (1998). Eye movements and measures of reading time. In G. Underwood (Ed.), Eye guidance in reading and scene perception (pp. 55-75). Amsterdam: Elsevier.

LyCAN, W. (1991). Even and even if. Linguistics \& Philosophy, 14, 115150 .

Mitchell, D. C., Shen, X., Green, M. J., \& Hodgson, T. L. (2008). Accounting for regressive eye-movements in models of sentence processing: A reappraisal of the selective reanalysis hypothesis. Journal of Memory \& Language, 59, 266-293. doi:10.1016/j.jml.2008.06.002

Moxey, L. M., Filik, R., \& Paterson, K. B. (2009). On line effects of what is expected on the resolution of plural pronouns. Language \& Cognitive Processes, 24, 843-875. doi:10.1080/01690960802634038

Ni, W., Crain, S., \& Shankweiler, D. (1996). Sidestepping garden paths: The contribution of syntax, semantics and plausibility in resolving ambiguities. Language \& Cognitive Processes, 11, 283-334. doi:10.1080/016909696387196

Ni, W., Fodor, J. D., Crain, S., \& Shankweiler, D. P. (1998). Anomalous strings: Eye-movement patterns. Journal of Psycholinguistic Research, 27, 515-539.

Paterson, K. B., Liversedge, S. P., Filik, R., Juhasz, B. J., White, S. J., \& RAYNER, K. (2007). Processing contrastive focus during silent reading: Evidence from eye movements. Quarterly Journal of Experimental Psychology, 60, 1423-1445. doi:10.1080/17470210601100563

Paterson, K. B., Liversedge, S. P., Rowland, C., \& Filik, R. (2003).
Children's comprehension of sentences with focus particles. Cognition, 89, 263-294. doi:10.1016/S0010-0277(03)00126-4

Paterson, K. B., Liversedge, S. P., \& Underwood, G. (1999). The influence of focus operators on syntactic processing of "short" relative clause sentences. Quarterly Journal of Experimental Psychology, 52A, 717-737. doi:10.1080/027249899391025

RAYNER, K., \& Duffy, S. A. (1986). Lexical complexity and fixation time in reading: Effects of word frequency, verb complexity, and lexical ambiguity. Memory \& Cognition, 14, 191-201.

Rayner, K., Warren, T., Juhasz, B. J., \& Liversedge, S. P. (2004). The effect of plausibility on eye movements in reading. Journal of Experimental Psychology: Learning, Memory, \& Cognition, 30, 12901301. doi:10.1037/0278-7393.30.6.1290

Rooth, M. (1992). A theory of focus interpretation. Natural Language Semantics, 1, 75-116.

SEDIvy, J. C. (2002). Invoking discourse-based sets and resolving syntactic ambiguities. Journal of Memory \& Language, 46, 341-370. doi:10.1006/jmla.2001.2812

Staub, A., Rayner, K., Pollatsek, A., Hyönä, J., \& Majewski, H. (2007). The time course of plausibility effects on eye movements in reading: Evidence from noun-noun compounds. Journal of Experimental Psychology: Learning, Memory, \& Cognition, 33, 1162-1169. doi:10.1037/0278-7393.33.6.1162

WARREN, T., \& MCCONNELL, K. (2007). Investigating effects of selectional restriction violations and plausibility violation severity on eyemovements in reading. Psychonomic Bulletin \& Review, 14, 770-775.

(Manuscript received August 4, 2008; revision accepted for publication March 13, 2009.) 